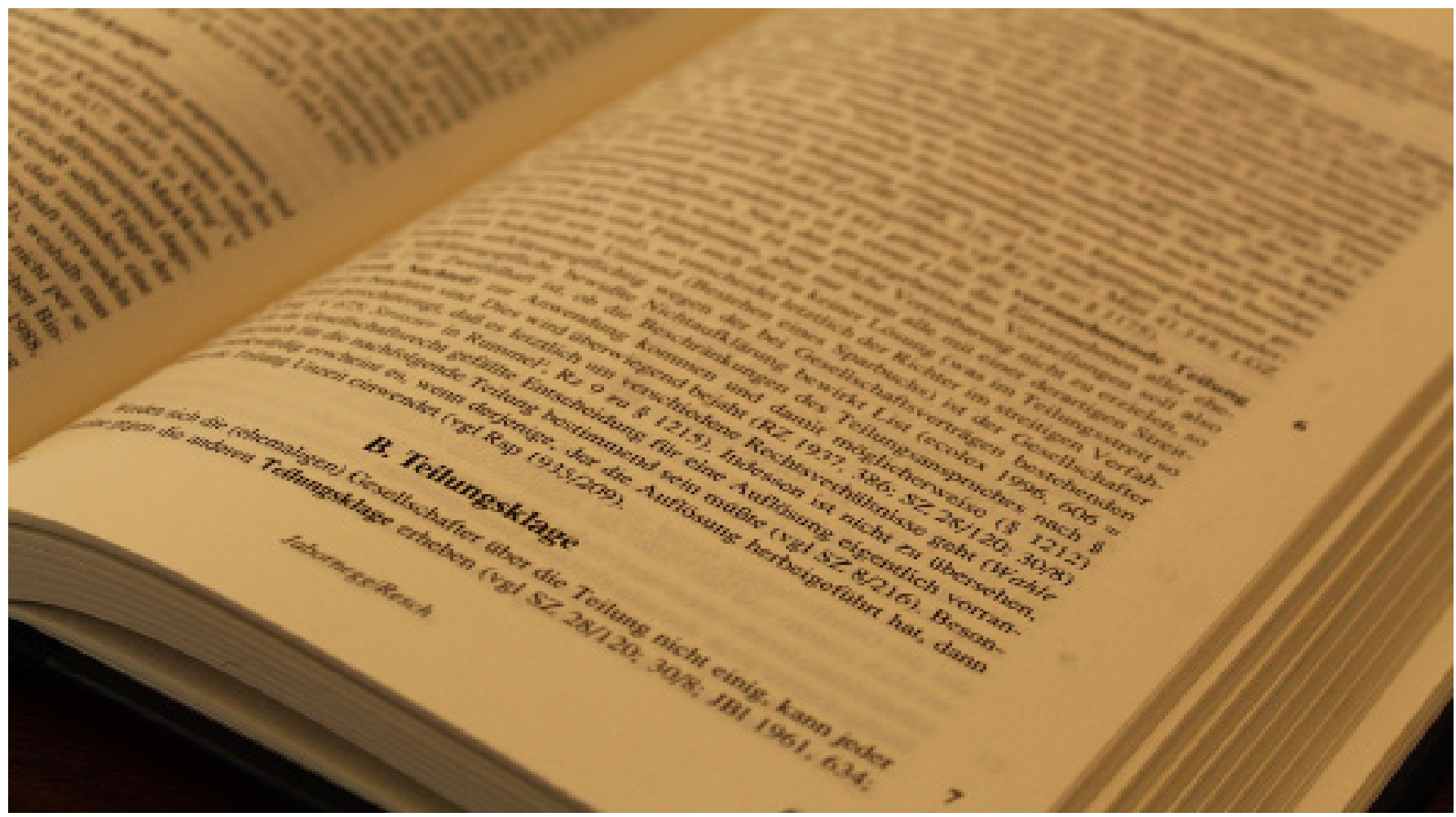

\title{
El Constitucionalismo interpretado en clave positivista: el Garantismo
}

\section{TheConstitutionalisminterpretedinpositivist key: the guarantee}

Indy Paola Nazir-Lleneris

Abogado-Candidato a Magister, indy_1222@hotmail.com,

https://orcid.org/0000-0001-9292-2886, Coordinador de investigaciones de la Facultad de Ciencias Sociales - FACS de la Fundación Tecnológica Antonio de Arévalo. Centro de Investigaciones Científicas y Tecnológicas de (CICTAR), Cartagena de Indias, Colombia. 


\section{Resumen}

El presente trabajo es un artículo de reflexión, en donde se esclarecerá, la postura desarrollada por Luigi Ferrajoli en su modelo Garantista como la base de una teoría del derecho, con ello pretendemos que el lector, conozca al Derecho y la razón a partir de las relaciones contingentes que sostiene con la moral; Así mismo, se declara la insostenibilidad dentro del mundo jurídico-fáctico- de las tesis de la separación y de la neutralidad, las cuales evocan a ficciones jurídicas tales como el legislador racional, el juez hércules, las críticas que le dirige al Estado de derecho liberal ; como objetivo específico de esta su obra es el modelo liberal; Ferrajoli fundamente su objetivo en la libertad, la moral y los derechos. El trabajo que nos ocupa finaliza, mostrando una panorámica haciendo una aseveración que sostiene que la Moral contingente propugna por los derechos fundamentales, y está acorde con los principios que pregona el Constitucionalismo, se muestra la potencialidad de este paradigma, ya que muestra la estructura y los mecanismos que permiten hacerlos efectivos en el Estado Constitucional, este modelo asegura la normativa de los derechos del más débil frente al poder estableciendo límites.

Palabras claves: Moral contingente, Garantismo, iuspositivismo crítico, legislador racional, juez hércules, legalismo ético.

\section{Abstract}

The present work is an article of reflection, where the position developed by Luigi Ferrajoli in his Guarantee model will be clarified as the basis of a theory of law, with this we intend that the reader, know the Law and the reason from the contingent relationships with morals; Likewise, the unsustainability within the legalfactual world of the theses of separation and neutrality is declared, which evoke legal fictions such as the rational legislator, the judge Hercules, the criticism that directs the rule of law liberal as a specific objective of this his work is the liberal model; Ferrajoli based his goal on freedom, morals and rights. The work at hand ends, showing an overview making an assertion that the contingent Moral advocates for fundamental rights, and is consistent with the principles proclaimed by Constitutionalism, shows the potential of this paradigm, as it shows the structure and the mechanisms that make them effective in the Constitutional State, this model ensures the regulation of the rights of the weakest against power by establishing limits.

Keywords: Moral contingent, Garantismo, critical iuspositivismo, rational legislator, judge hercules, ethical legalism. 


\section{0}

\section{Introducción}

En el mundo actual surge un sinfín de cambios a nivel social, económico y político, creando así la necesidad de comprender los causantes a nivel negativo en la función pública, igualmente conseguir posibles soluciones de las mismas, en el entendido que afectan directamente al bienestar social, por lo tanto, es imprescindible tener conocimientos pleno de las actuaciones antes estas afectaciones sobre el individuo [1].

Así mismo, como individuos sumergidos en la sociedad no sujeta algo fundamente como lo es el derecho, así se evidencia en [2] Los derechos fundamentales se afirman siempre como leyes del más débil en alternativa a la ley del más fuerte que regía y regiría en su ausencia. La interpretación del Derecho, bien sea como teoría del Derecho o como Derecho mismo, obedece a un sin número de variables y externalidades.

Para muchos, dichas externalidades se traducen en contingencias históricas. Para entender las contingencias, ambiciosa tarea, a decir verdad como a bien tenga llamárseles, se han ideado una serie de modelos de interpretación del Derecho dependiendo reivindicados y positivamente conquistados a la moral como contingente de la inclusión, vinculación o exclusión de la Moral. Estas relaciones de dependencia o declaraciones de separación absoluta están sujetas a lo que se entienda por Moral; en [3] la ética y la moral son las armas principales para combatir las prácticas indebidas de los miembros de la organización, sin embargo, su práctica requiere permanentemente estímulo.

Por consiguiente, se esbozarán los elementos más importantes del garantismo, la ética, la mora mediante en modelo de Luigi Ferrajoli, realizando una reflexión del mismo, quien siempre hablo en sus obras sobre el constitucionalismo desde una concepción positivista del Derecho, se podrá observar que el autor en sus obras busca siempre que el Derecho regule la vida social.

El constitucionalismo interpretado en clave positivista

Una de las formas de elucidar al Derecho es mediante el Modelo Garantista de Luigi Ferrajoli. Inicialmente, este modelo fue desarrollado en el ámbito del Derecho Penal, para más tarde considerarse aplicable a todas las ramas del Derecho. Vale decir de inmediato que el modelo se fundamenta en una concepción positivista del Derecho, más exactamente un luspositivismo crítico. La tesis central de este modelo garantista parte del reconocimiento y materialización de los Derechos Fundamentales [4]. A partir de esta postura se evoca un cambio estructural en la aplicación del Derecho y la concepción de la Democracia.

Estos cambios estructurales obedecen a contingencias históricas que se sitúan en el tránsito del Estado liberal al Estado Constitucional [5], locual supone una progresiva evolución de los derechos paulatinamente reivindicados y positivamente conquistados mediante la inclusión en las Cartas Políticas. Estos cambios son producto de los avatares de las sociedades, que generan fluctuaciones en la comprensión del Derecho y sus alcances, provocando un levantamiento de los individuos que la conforman. La divergencia empírica o fáctica, que la teoría del derecho expresa en la distinción entre normatividad y eficacia, se manifiesta en la ineficacia del derecho, que en el estado de derecho afecta no sólo a los individuos sino también, y diría sobre todo, a los poderes públicos, y se resuelve en el funcionamiento ilegal o extra-legal de las instituciones [6].

Ahora bien, hablar de Moral Contingente dentro de un luspositivismo Critico resultaría 
incongruente, si no se tiene claridad de la Moral propuesta por Ferrajoli. Como se señaló en un principio, la inclusión, vinculación o exclusión de la Moral en la Teoría del Derecho depende de lo que se entienda por Moral. No obstante, a lo largo de la historia del Derecho, en el afán de la positivización y la marcada tendencia a la cuantificación del mismo, se ha estado en desacuerdo en vincular a una moral abstracta. La ética y la moral son las armas principales para combatir las prácticas indebidas de los miembros de la organización, sin embargo, su práctica requiere permanentemente estímulo [3].

Por ello, sostener el criterio valorativo de la moral en el actuar de los individuos, a nuestro parecer, resulta acertado; esta visión se traduce en un intervencionismo social, dejando de lado la conducta abúlica que había caracterizado a las sociedades de antaño. Estamos en presencia de un cambio de posición del ciudadano promedio, quien ya no puede considerarse a sí mismo como un espectador distante, sino como un regulador del acontecer normativo. Los derechos se configuran como vínculos sustanciales impuestos a la democracia política; existen los vínculos negativos generados por el derecho a la libertad, por otro lado están los vínculos positivos, generados por los derechos sociales que ninguna mayoría puede dejar de satisfacer. [7]

La mentada participación de los individuos que conforman la sociedad, redunda en el argumento Democrático. Es menester señalar que las mayorías de las constituciones actuales son democráticas por cuanto este ha sido el Sistema de Gobierno considerado más apropiado para la organización y el despliegue del Poder Público. Sin embargo, existen visiones desacertadas que arremeten contra el luspositivismo crítico planteado por Ferrajoli, interpretando al Constitucionalismo actual en clave anti positivista. La discusión contemporánea sobre la actualidad y relevancia del positivismo se centra en su compatibilidad con una cierta visión de las constituciones contemporáneas a las que se atribuye un rol fundamental en dar una identidad específica a los sistemas jurídicos [8].

Una de las críticas acérrimas en contra del Positivismo no sabemos exactamente a cual positivismo se refiere, en el entendido de los postulados y transformaciones que este ha sufrido en [9] identifica al Positivismo Jurídico a través de la "tesis de la separación" y la "tesis de la neutralidad La primera de ellas sostiene que no existe una relación conceptual entre el Derecho y la Moral, pero esta negación de toda conexión es claramente insostenible, porque en todos los sistemas jurídicos se expresa así sea la Moral de los Legisladores; a menos, que se tome como punto de partida una ficción, como lo es la del Legislador Racional. Aun así, esto quedaría en el plano ideal, puesto que la tesis tendría un soporte meramente ficcional, que no llegaría al campo factico.

Por otra parte, tendríamos la tesis de la Neutralidad, que Ferrajoli señala como de pura descriptivita o neutralidad valorativa. Ahora bien, hemos señalado que la tesis de la separación resulta a todas luces insostenible, entonces ¿Cómo podríamos defender una postura neutral? Esta acepción nos conduce a un juicio más radical, como es la imparcialidad absoluta, aquello que no se inclina hacia ningún lado de la balanza y que por tanto no es ni de uno, ni de otro. Para algunos se traduciría en falta de criterio, para nosotros en un criterio ampliamente ideológico, que no obedece al SER del Derecho. Cuando hablamos de imparcialidad judicial, lo hacemos desde una perspectiva constitucional como parte del debido proceso y seguridad jurídica, así también, como un elemento que legitima la toma de decisiones de los jueces y de la fiabilidad del sistema judicial en su totalidad [10]. 


\section{2}

Esta supuesta neutralidad no tiene transcendencia en el Derecho en el plano factico, es decir, si se toma el Imperativo Jurídico que sostiene que toda forma de Poder está sujeta al Derecho, ya sea en el plano del procedimiento o creación de la norma, o bien sea en el contenido de las decisiones cuando la norma se aplica, dicha neutralidad solo se predicaría en un plano ideal. Por tanto, no solo se acudiría a la ficción del Legislador Racional, sino que para justificar el carácter neutral de las decisiones judiciales, tendría que recurrirse a una segunda ficción: la del Juez Hércules.

De allí la connotación de supuesta de esta tesis. Para Ferrajoli el garantismo no es sino una profundización del positivismo jurídico en un doble sentido. Por un lado, lleva el principio del normativismo hasta sus últimas consecuencias al condicionar la validez de las normas a los contenidos incorporados a la Constitución [11].

Una segunda critica, con exactitud no se sabe si es más o menos radical que la anterior; lo que sí sabemos es que le endilga ciertas características negativas que nada tienen que ver con el Positivismo Jurídico en [12] se señala que el positivismo es una teoría adecuada para dar cuenta del Derecho del Estado Constitucional, siempre y cuando pueda asumir principios morales como criterios de validez jurídica.

De lo anterior se colige que sostiene la tesis de una conexión necesaria entre el Derecho y la Moral. Dicha conexión la fundamenta, por una parte, en una idea ético-constitucionalista, donde las Constituciones se soportan en una legitimidad moral, y por otra, en una idea iusnaturalista que asume la justicia como una condición de validez.

En principio, hay una mezcla entre el iusnaturalismo y el legalismo ético, pilares en los que soporta en [12] su tesis. Esta mezcla no puede ser considerada homogénea, ya que una visión se fundamenta en la justicia -que es una categoría dogmática-, mientras que el legalismo se soporta en la legitimidad moralque es una categoría eminentemente política con una marcada tendencia social, claro está, entendida como una moral objetiva.

De este modo, Los derechos fundamentales se constituyen también en base de la democracia, sea formal o sustancial, debido a que son necesarios para su establecimiento. Dado que los derechos civiles y políticos determinan el quién y el cómo, son ellos (como derechospoder, de autonomía o secundarios) la base de la democracia formal [13]; se podría categorizar esta mixtura, como una inconsistencia, pero a nuestra consideración, se traduce en una indeterminación al momento de validar la tesis sobre la conexidad necesaria, y en vista que no es posible cercenar al luspositivismo Critico mediante una posición, entonces acudo a una postura más ecléctica pero no del todo compatible; en [14] se evidencia que constitucionalismo garantista como un iuspositivismo reforzado, completando al Estado de Derecho porque comporta el sometimiento al Derecho y al control de constitucionalidad.

\section{Conclusiones}

Se concluye que el Positivismo Jurídico, planteado por Ferrajoli, es aquel producto de transformaciones y circunstancias históricas, que nos permite hablar de un positivismo incluyente cimentado en una Moral contingente que propugna por los derechos fundamentales, estando acorde con los principios que pregonan las constituciones actuales y que por ende es compatible con el Constitucionalismo; el garantizo no es sino una profundización del positivismo jurídico en un doble sentido, permite una visión de los derechos de los más débiles, de la moral 
y la ética, valores que deben prevalecer ante cualquier decisión que necesite imparcialidad.

Referencias

[1] L. Ferrajoli, Derechos y Garantías. La ley del más débil. Madrid, España: Editorial Trotta S.A, 2002

[2] J. Torres Ávila, “La teoría del Garantismo: poder y constitución en el Estado contemporáneo", Revista de Derecho, no. 47, 2017

[3] Y. Vilchez, "Ética y moral una mirada desde la gerencia pública", Revista Formación Gerencial, vol. 11, no. 2, pp. 232-247, 2012

[4] F.J Ansuátegui Roig, Derechos fundamentales y dignidad humana, Madrid, España: Universidad Carlos III de Madrid. Instituto de Derechos Humanos Bartolomé de las Casas, 2011

[5] M. Carbonell, P. Salazar, Garantismo, estudios sobre el pensamiento jurídico de Luigi Ferrajoli, Madrid, Esáña, Editorial Trotta S.A. 2005.

[6] L. Ferrajoli, La teoría del derecho en el sistema de los saberes jurídicos. Madrid: Fundación Coloquio Jurídico Europeo. pp. 117-132. 2008

[7] R.E. Aguilera Portales y R. López Sánchez, Los derechos fundamentales en la teoría jurídica garantista de Luigi Ferrajoli, Distrito Federal, México: Biblioteca Jurídica Virtual del Instituto de Investigaciones Jurídicas de la Universidad Nacional Autónoma de México

[8] R. Marquisio, "Argumentos positivistas en la era postpositivista”, Revista de Derecho no.19, jun 2019.

[9] A.J García Figueroa, Las tensiones de una teoría cuando se declara positivista, quiere ser crítica, pero parece neoconstitucionalista,
Garantismo: Estudios sobre el pensamiento jurídico de Luigi Ferrajoli pp. 267-284, 2005

[10] I. Abad, J. Camacho, G. Capelo, D. Chiliquinga y S. Olalla. "La imparcialidad judicial" Revista jurídica, no. 31, pp. 141-152, Junio 2018.

[11] F. Mora Sifuentes, "El garantismo como constitucionalismo de reglas", en 1er Encuentro de Jóvenes Investigadores de la Sociedad Española de Filosofía Jurídica y Política: Neoconstitucionalismo en tiempos de postdemocracia Universitat de València, 2012

[12] M. Iglesias, El positivismo en el Estado constitucional. Algunos comentarios en torno al constitucionalismo de Ferrajoli, Madrid, España: Editorial Trotta, 2005.

[13] J. Gaviria Mira, “Constitucionalismo garantista: democracia y soberanía popular sin pueblo", Revista chilena de derecho, vol. 46 no.1 Santiago abr. 2019

[14] L. Ferrajoli, "Constitucionalismo principialista y constitucionalismo garantista". Doxa. Cuadernos de Filosofía del Derecho, no. 34, pp. 15-53, 2011 